\title{
Monitoramento e Controle Metacognitivo na Resolução de Problemas em Física: Análise de um Estudo Comparativo
}

\author{
Monitoring and Control Metacognitive in Solving Problems in \\ Physics: Analysis of a Comparative Study
}

\author{
Cleci T. Werner da Rosa ${ }^{\mathrm{a}}$; Caroline Maria Ghiggi ${ }^{\mathrm{a}}$ \\ a Universidade de Passo Fundo, Passo Fundo, Brasil - cwerner@upf.br, caroline.ghiggi@ hotmail.com
}

Palavras-chave:

Resolução de problemas. Metacognição. Física.

Ensino Médio.
Keywords:

Problem-solving.

Metacognition. Physics. High school.
Resumo: O presente trabalho tem a finalidade de investigar a atividade de resolução de problemas do tipo lápis e papel, em termos da importância de se favorecer aos estudantes momentos de tomada de consciência sobre seus conhecimentos, de estimular a monitoração e de exercer o controle das ações. De forma mais específica, o estudo busca avaliar o desempenho acadêmico dos estudantes do ensino médio em situações de resolução de problemas do tipo lápis e papel, quando guiados por instruções que levam à necessidade de reelaborar o enunciado e ilustrar o problema utilizando os seus conhecimentos prévios. O embasamento teórico encontra-se vinculado à inserção de estratégias de aprendizagem metacognitivas como possibilidade de auxiliar os estudantes na compreensão e solução dos problemas em Física. A investigação, de cunho qualitativo, busca analisar e comparar duas turmas de primeiro ano do ensino médio - sendo uma orientada para recorrer ao pensamento metacognitivo e outra não quanto aos seus desempenhos acadêmicos, diante de quatro problemas clássicos de cinemática. Os resultados apontam que a proposta didática envolvendo o uso de estratégia de aprendizagem metacognitiva mostra-se mais eficiente em termos de diálogos dos alunos com os problemas apresentados, na busca por solucionar os problemas, e do número de acertos nas questões propostas.

Abstract: The present work aims to investigate the activity of pencil-paper problem solving regarding the importance of providing students with moments of awareness about their knowledge, stimulation of monitoring, and exercise of control over actions. Particularly, the study seeks to assess academic performance of high school students in pencil-paper problem solving situations, guided by instructions that require them to recreate the title and illustrate the problem using their previous knowledge. The theoretical basis is linked to the introduction of metacognitive learning strategies as potential aid for students in understanding and solving Physics problems. The qualitative investigation seeks to analyze and compare two classes of the first year of high school - one class was instructed to use metacognitive thinking and the other one was not - regarding their academic performances faced with four classic kinematics problems. The results indicate that the didactic proposal involving the use of metacognitive learning strategies is more efficient in terms of student dialog with the problems presented aiming to solve them, and the number of right answers in the questions proposed. 


\section{Introdução}

Dentre as áreas abordadas nas pesquisas de Ensino de Física, a resolução de problemas destaca-se com um relevante número de estudos (PEDUZZI et al., 1992; COSTA; MOREIRA, 1996; 1997; SOUZA; FÁVERO, 2003; CLEMENT, 2004, CLEMENT; TERRAZAN, 2012; GÓMEZ-FERRAGUD et al., 2016). Tal situação é justificada considerando que essa estratégia didática ocupa praticamente todo o programa de ensino da disciplina de Física durante o ensino médio.

Essa ênfase na resolução de problemas está ligada à concepção que a maioria dos professores tem de que, para aprender Física, é necessário resolver problemas, basicamente os do tipo lápis e papel. O excessivo número dessas atividades nos livros didáticos de Física pode ser a raiz de tal concepção, ou, ainda, as exigências das provas de avaliações que os alunos realizam, como o Exame Nacional do Ensino Médio (ENEM) e no vestibular, que priorizam esse tipo de estratégia didática.

Todavia, na mesma direção em que é utilizada como atividade majoritária no ensino de Física, a resolução de problemas vem sendo assinalada como uma das causas do fracasso de muitos alunos na aprendizagem dessa componente curricular. De acordo com Costa e Moreira, esta se trata de uma atividade complexa que envolve pensamento, sendo preciso "entendê-la melhor com o objetivo de reverter essa situação" (1996, p. 177).

Dentre as possíveis razões para essa associação infrutífera, está a ideia preestabelecida de que os problemas a serem resolvidos consistem em aplicações diretas de fórmulas, contendo um conjunto de dados muitas vezes descontextualizado e irreal para os estudantes. Em outras palavras, problemas de lápis e papel, frequentemente utilizados no ensino (e na avaliação do ensino), não representam situações reais e vivenciadas pelos alunos, seja em um contexto próximo ou remoto.

Tal panorama tem levado a que os alunos entendam a resolução de problemas como resolução matemática, algébrica, na qual é apresentada uma situação problema, cabendo-lhes extrair os dados e aplicá-los em uma fórmula. Dificilmente os alunos, durante a leitura do problema, analisam a questão apresentada de forma a confrontá-la com a realidade, ou mesmo exercitam seu pensamento associando ao apresentado a possibilidade física da situação. Isso contribui para a inconsistência em dados ou mesmo na resposta, que dificilmente é percebida pelos alunos.

Desse modo, a resolução de problemas de lápis e papel vem sendo objeto de discussão tanto das pesquisas no campo da Psicologia Cognitiva como do Ensino de Física. Aliás, é na Psicologia Cognitiva que os pesquisadores desta última área têm buscado seus aportes 
teóricos para subsidiar suas investigações e propostas de melhoria do ensino dessa disciplina, principalmente quando a preocupação está na aprendizagem.

É o caso do presente estudo, cujo embasamento teórico encontra-se vinculado à inserção de estratégias de aprendizagem metacognitivas como possibilidade de auxiliar os estudantes na compreensão e solução dos problemas em Física, por meio da tomada de consciência sobre seus conhecimentos e ações. As estratégias de aprendizagem metacognitivas envolvem "o planejamento, a monitoração e a regulação do próprio pensamento" (ROSA, 2011, p. 82). Portanto, utilizá-las na aprendizagem significa planejar, monitorar e avaliar a ação, o que, neste estudo, é traduzido por monitorar e controlar a ação. $\mathrm{O}$ planejamento é entendido como algo que antecede a monitoração e, no caso deste estudo, faz parte da ação do professor ou das instruções dadas pelo material fornecido pelos pesquisadores. A monitoração, por sua vez, representa a capacidade de "controlar a ação e verificar se está adequada para atingir o objetivo proposto, avaliando o desvio em relação a este, percebendo erros e corrigindo-os, se necessário" (ROSA, 2011, p. 55). O controle da ação, por sua vez, é definido como sendo a capacidade de avaliar "os resultados atingidos em face do fim visado" (ROSA, 2011, p. 56).

A opção por investigar a capacidade que os estudantes têm de monitorar e controlar suas ações durante a realização de problemas em Física está associada aos seguintes questionamentos, os quais se pretende discutir neste trabalho: a inserção de problemas contextualizados e que levem os alunos a estabelecerem um modelo ilustrativo da situação problema favorece a busca pela sua resolução? O aluno entende e é capaz de fazer uma representação adequada da situação problema apresentada? Pensar nela e representá-la favorece a monitoração e o controle da ação?

Tais questionamentos definem como objetivo do estudo investigar a resolução de problemas em alunos que são instigados a criar representações das situações por meio da tomada de consciência de seus conhecimentos. De forma mais específica, busca-se avaliar o desempenho acadêmico de estudantes do ensino médio em situações de resolução de problemas do tipo lápis e papel, quando guiados por instruções que levam à necessidade de reelaborar o enunciado e ilustrar o problema utilizando os seus conhecimentos prévios.

Em termos da importância do pensamento metacognitivo na aprendizagem, Chin et al. (1982), ao mencionarem a diferença entre alunos considerados novatos e especialistas em Física. Os primeiros são os que demonstram dificuldades para resolver problemas em Física e tradicionalmente apresentam as piores avaliações na disciplina. Os autores destacam que uma das diferenças entre os dois tipos de estudantes está no uso do pensamento metacognitivo. Os especialistas, que são os que apresentam facilidade na resolução dos problemas em Física, 
pensam de forma a explorar o controle executivo da ação, o que leva a um pensar antes de fazer.

Tal situação é corroborada por Costa e Moreira ao afirmarem que "os professores devem abordar de forma incisiva, fatores metacognitivos de análise da tarefa" (2006, p. 157). Destaca-se, assim, a necessidade de que as estratégias de aprendizagem metacognitivas se façam presentes e constituam elementos do ideário dos professores em suas atividades didáticas.

Nesse sentido, Coleoni et al. (2001) entendem que os alunos novatos são guiados pelas equações, além de precisarem de metas parciais para concluir as situações problema. Os alunos especialistas, por sua vez, buscam criar uma representação mental da situação física, por já utilizarem os referidos recursos metacognitivos de controle executivo e autorregulador que permitem ter consciência do problema, dos conhecimentos prévios de que dispõem e dos que lhes são requisitados.

Continuam os autores relatando que a resolução de um problema inicia com a leitura e compreensão do enunciado, assim como "o resultado da compreensão de um texto inclui informação adicional a partir do conhecimento do leitor" (COLEONI et al., 2001, p. 287). Portanto, é a partir da tomada de consciência do aluno acerca dos seus conhecimentos prévios e dos conhecimentos necessários para determinada situação problema que ele irá construir uma representação a ela correspondente. Cabe analisar os níveis dessas representações:

O nível superficial corresponde à formulação exata do texto com as mesmas palavras e estrutura sintática do mesmo. Esta é uma representação que sobrevive na memória rapidamente e tem menos interesse para os nossos propósitos. O segundo nível de representação é a base de texto, que consiste essencialmente na representação do sentido do texto na forma de proposições. [...]. As propostas neste nível de representação surgem diretamente do texto. No entanto, em geral, o resultado da compreensão de um texto inclui informação adicional a partir do conhecimento do leitor. Um terceiro nível de representação que também inclui outras propostas da memória do leitor, ou seja, sua base de conhecimento (COLEONI et al., 2001, p. 287, tradução nossa).

Esse terceiro nível de representação desperta um interesse maior, pois, ao utilizar sua base de conhecimentos para construir suas representações mentais, o sujeito estará ancorando as novas informações nas que já estão disponíveis em sua estrutura cognitiva, possibilitando, assim, uma aprendizagem significativa durante a resolução de problemas. Logo, a partir de relações formais do conhecimento físico, ele poderá fazer sua representação do mundo.

Ao ler o enunciado de um problema de física, a capacidade de um sujeito para construir um modelo da situação que representa o evento em situações do cotidiano, ou outro envolvendo relações formais estruturalmente, depende do conjunto de esquemas disponíveis (qualidade e quantidade) e das estratégias de recuperação (COLEONI et al., 2001, p. 287, tradução nossa).

Para estudantes habituados a uma resolução tradicional, tentando apenas "encaixar peças" dentro de uma fórmula, trabalhar com uma estratégia que resgate seus esquemas e 
estimule suas representações mentais surge como uma possibilidade de melhorar o panorama da resolução de problemas, tão presente no ensino de Física.

\section{Revisão de literatura}

A resolução de problemas como estratégia didática é muito utilizada nas áreas das Ciências e de Matemática, resultando em uma numerosa gama de pesquisas, conforme já mencionado. Lester (1985), em seus estudos referentes à resolução de problemas em Matemática, propõe um modelo composto por quatro componentes cognitivas, as quais estão associadas às componentes metacognitivas: orientação (leitura, análise e compreensão do problema); organização (identificação das estratégias e concepção de um plano de resolução); execução (implementação das estratégias e do controle do progresso); e verificação (as que ocorrem com a avaliação das fases anteriores). A aplicação desse modelo remete o estudante à necessidade da tomada de consciência da atividade que está realizando.

Polya (1985), um dos matemáticos mais destacados do século XX, elaborou uma sequência de quatro etapas referentes à resolução de problemas em matemática e que igualmente estão identificadas com a metacognição. São elas: compreender o problema (o primeiro passo é entender o problema, por meio de perguntas como: qual é a incógnita? Quais são os dados? Quais são as condições? É possível satisfazer as condições?); estabelecer um planejamento (encontrar conexões entre os dados e a incógnita. Você conhece um problema semelhante?); planificar a resolução do problema; executar o plano (ao executar, verifique cada passo. Você consegue mostrar que cada um deles está correto?); e revisar a solução (você deve examinar a solução obtida, verificando os resultados e os argumentos utilizados. Você pode obter a solução de algum outro modo? É possível usar o mesmo método na resolução de algum outro problema?). Segundo o autor:

Estas perguntas são exemplos de uma Heurística prática e de bom senso. O professor deve utilizá-las, de início, nos casos onde elas facilmente sugerem a ideia correta ao aluno. Depois ele poderá utilizá-las cada vez mais, tão frequentemente quanto o discernimento e o tato o permitirem (POLYA, 1985, p. 3).

Com o tempo, o estudante poderá usar espontaneamente esse método, dirigindo sua atenção aos pontos essenciais na resolução do problema, de modo a regular sua própria aprendizagem.

No ensino de Química e Física, Leite e Esteves (2005) abordam aspectos relevantes acerca da aprendizagem baseada na resolução de problemas, desde suas concepções epistemológicas até suas aplicações didáticas. No estudo, as autoras investigam a estratégia de ensino baseada em resolução de problemas em uma turma de licenciandos em Física e Química. Como resultado, verificam que grande parte dos estudantes motivou-se com as estratégias e participou com mais envolvimento do processo de ensino-aprendizagem. Um 
ponto que chama atenção das pesquisadoras é que a autonomia do sujeito revela-se fundamental. Segundo elas, "quando [os estudantes] são envolvidos em contextos de ensino que rompem com os seus hábitos, necessitam de tempo para se habituarem a aprender a aprender" (LEITE; ESTEVES, 2005, p. 1766). Partindo das reflexões dos participantes da pesquisa, as pesquisadoras concluem que eles tomaram consciência das dificuldades, de seu papel na aprendizagem e das lacunas no conhecimento. Logo, a estratégia teve efeitos metacognitivos.

Nas pesquisas voltadas exclusivamente ao ensino de Física, a resolução de problemas com estratégias metacognitivas também é promissora. Souza e Fávero (2002) centram seu estudo em uma proposta de procedimento para resolução de problema que privilegia trocas verbais entre especialistas e novatos em situação de interação social, a fim de evidenciar regulações cognitivas em relação a um campo conceitual particular. No trabalho que relatam, foi criada uma situação de interação que permite intervir nas operações de regulação, de tal forma que o sujeito pode revisar o processo de produção em um campo conceitual próprio da Física, almejando a reelaboração das ações produtos na resolução de problemas. $\mathrm{O}$ estudo foi conduzido de maneira compatível com a proposta da teoria dos campos conceituais de Vergnaud, utilizando a metacognição como elemento subjacente à situação proposta, ou seja, por sua proximidade com os mecanismos regulatórios. A pesquisa foi desenvolvida com dois alunos em nível de ensino médio que cursam pré-vestibular, por meio de cinco sessões individuais nas quais foram abordadas resoluções de problemas em conteúdo de eletricidade. A análise da interação foi considerada com base na fala dos estudantes durante a resolução de problemas em Física e da sua tomada de consciência frente aos problemas propostos. Segundo as pesquisadoras, a tomada de consciência refere-se tanto a ter consciência da situação de intervenção como do papel de cada sujeito (professor e estudante) na interação social. Além disso, avaliam que ela está vinculada à tomada de consciência do próprio aprendiz em relação à sua cognição no processo de resolução de problema.

$\mathrm{Na}$ investigação de Neto e Valente (2001), o foco é a resolução de problemas na disciplina de Física sob uma orientação metacognitiva. Os autores levam em consideração elementos vygotskyanos para orientar a proposta, principalmente no que se refere à zona de desenvolvimento proximal dos estudantes. Eles abordam que o ensino do modo como acontece tradicionalmente não estimula o potencial de desenvolvimento dos alunos, defendendo, então, um ensino que os conscientize acerca do seu conhecimento e que não seja apenas mecanizado. A partir dessas ideias, os autores analisam a eficiência dos sujeitos na resolução de problemas com base em enunciados mais próximos das situações cotidianas, utilizando, também, estratégias metacognitivas. O estudo buscou verificar a potencialidade das atividades no desenvolvimento de experiências metacognitivas (comportamento, hábitos e 
atitudes) e em que medida elas podem contribuir para uma mudança positiva dos estudantes diante da relação entre a Física e a resolução de seus problemas. O resultado da pesquisa apontou para a viabilidade dessa metodologia. Entretanto, os autores chamam a atenção para outros contingentes que necessitam ser alterados, como os de ordem estrutural e organizacional, e, ainda, para a necessidade de que os professores estejam preparados para esse ensino, destacando que eles é que são os verdadeiros promotores da mudança no ensino.

O estudo de Gómez-Ferragud et al. (2016) e mais próximo dos propósitos deste estudo descrevem quatro estudos de natureza empírica. O primeiro voltado à análise das primeiras etapas do processo de transferência, codificação e estabelecimento de analogias. O segundo estudo associado à relação entre a resolução de problemas de forma correta e o uso de analogias. $\mathrm{O}$ terceiro estudo voltado a identificar as dificuldades cognitivas dos estudantes durante a resolução de problemas. E no último estudo dirigido ao uso de estratégias metacognitivas de controle da compreensão de um problema resolvido. Como resultado dos estudos, os autores apontam que no primeiro caso investigado, os alunos apresentam dificuldades de percepção e de uso da estrutura dos problemas para sua codificação; no segundo caso, mostram haver dificuldades na resolução de problemas especificamente no caso dos estudantes novatos em situações que não envolvem situações vivencias; no terceiro estudo, os resultados apontaram novamente a dificuldade dos estudantes frente a situações não familiares, mas também evidenciaram que a transferência entre os problemas e o contexto vivencial não é imediata para os alunos necessitando que os professores auxiliem nesse processo; e, por fim, no último estudo, ficou evidenciado o baixo nível de controle da compreensão por parte dos estudantes, sendo destacado pelos autores que sem um controle adequado sobre o que se sabe ou o que não se sabe é difícil aprender a resolver problemas em Física.

Ainda considerando a proximidade com o objeto de estudo procede-se na continuidade uma revisão no conceito de metacognição de modo a fornecer elementos para a compreensão das atividades desenvolvidas e apoiadas nessa perspectiva teórica. Para tanto, toma-se como referência trabalhos anteriores desenvolvidas pela primeira autora deste artigo (ROSA, 2011; 2014).

O papel exercido pelo pensamento metacognitivo na aprendizagem pressupõe o "conhecimento que o sujeito tem sobre seu conhecimento e a capacidade de regulação dada aos processos executivos, somada ao controle e à orquestração desses mecanismos" (ROSA, 2011, p. 57). Esse entendimento compreende duas componentes: o conhecimento do conhecimento e o controle executivo e autorregulador.

A primeira componente é entendida como o conhecimento metacognitivo e refere-se ao conhecimento, crenças, ideias e teorias sobre como as pessoas são enquanto criaturas 
cognitivas e sobre suas interações com as diversas tarefas e estratégias cognitivas. Esse conhecimento metacognitivo de acordo com Flavell e Wellman (1977) inclui três subcategorias assim identificadas: conhecimento sobre pessoas, tarefas e estratégias. $\mathrm{O}$ conhecimento sobre as pessoas encontra-se vinculado ao conhecimento das variáveis que influenciam a atividade cognitiva do indivíduo, o conhecimento da cognição dos outros e conhecimento da cognição universal das pessoas. O conhecimento de tarefas refere-se à compreensão de como as condições da natureza das tarefas, demandas e objetivos afetam a atividade cognitiva. Por fim, o conhecimento das estratégias se refere ao conhecimento sobre o pensamento, a aprendizagem e as estratégias de resolução de problemas que os estudantes podem usar para atingir as metas.

O controle executivo e autorregulador estão associados de acordo com Rosa (2011; 2014) com a capacidade de planejar, monitorar e regular as ações. O planejamento envolve a definição de objetivos, a seleção de estratégias apropriadas, fazer previsões, estratégia de sequenciamento e alocação de recursos. O monitoramento envolve a consciência imediata da compreensão e do desempenho em determinadas tarefas ou na aprendizagem. Avaliação implica uma avaliação dos produtos e eficiência de sua aprendizagem e pensar, por exemplo, através da autorreflexão e reavaliação ação desenvolvido e se os objetivos foram alcançados.

Do exposto, tem-se que a metacognição, enquanto mecanismo ativador do pensamento, está associada às estratégias de aprendizagem, que, por sua vez, diferenciam-se das de natureza cognitiva. As metacognitivas são responsáveis por auxiliar os estudantes no planejamento, na monitoração e na regulação do próprio pensamento. Elas representarem processos mentais que buscam capacitar os estudantes a identificarem seus conhecimentos e controlarem suas ações, permitindo-lhes realizar tarefas de forma a obterem maior êxito. Pesquisadores como Campanario e Otero (2000) enfatizam que as estratégias de aprendizagem metacognitivas têm sido apontadas como relevantes quando aproximadas do ensino de Física (Ciências), na medida em que podem atuar como mecanismos que detectam falhas de compreensão nos estudantes. Os autores (CAMPANARIO; OTERO, 2000) evidenciam que essa situação permite identificar a razão dessas falhas, levando-os a buscar alternativas de solução. Salientam, ainda, que as dificuldades de aprendizagem podem estar relacionadas a concepções errôneas, cuja identificação, via metacognição, pode ser mais frutífera e proveitosa, pois atua no plano da tomada de consciência, o que favorece seu reconhecimento, abrindo caminho para a construção do novo conhecimento.

\section{Metodologia}

Com vistas a responder aos questionamentos iniciais e atingir o objetivo do estudo, desenvolve-se uma pesquisa do tipo qualitativa e descritiva, na qual se busca, por meio da 
coleta de dados, analisar e descrever um fenômeno. No estudo qualitativo, de acordo com Triviños (1994), os dados são trabalhados de forma a se buscar seu significado, tendo como base a percepção do fenômeno dentro do seu contexto. Na pesquisa descritiva, segundo Gil (2008), persegue-se a descrição das características de um determinado fenômeno ou experiência.

Os encaminhamentos para a realização da pesquisa ocorreram de modo a responder aos questionamentos iniciais, especialmente em termos de avaliar a capacidade de monitoração e controle dos estudantes mediante uma situação guiada por estratégias metacognitivas, analisando sua eficácia. Dessa forma, o estudo analisou os resultados da aplicação de um teste, contendo quatro questões dissertativas na forma de problemas do tipo lápis e papel, como os tradicionalmente presentes no livro didático. Foram selecionadas duas turmas de primeiro ano, sendo uma com 24 alunos e tida como turma A (TA), na qual não haveria inferência dos pesquisadores, e a outra, com 25 alunos, considerados como turma B (TB), na qual os estudantes seriam orientados sobre como proceder para resolver os problemas propostos.

A pesquisa foi realizada em uma escola pública do município de Passo Fundo - RS. Cabe esclarecer que as turmas participantes foram consideradas, pela professora titular, como de rendimento acadêmico equivalente. O material foi elaborado com quatro questões de Física estruturadas de forma semelhante às das utilizadas pela professora. Nesse sentido, destaca-se que o material foi elaborado depois de um diálogo entre os pesquisadores e a professora, por meio do qual foi possível obter informações sobre as turmas, o conteúdo, o livro didático utilizado, bem como sobre a forma como os problemas eram abordados em sala de aula. Com base nesses dados, selecionaram-se quatro situações problema relacionadas à cinemática. As duas turmas envolvidas foram devidamente orientadas sobre como deveriam resolvê-las.

Na turma A, os alunos foram orientados a resolver as questões como estão habituados, entretanto, sem terem acesso a materiais de apoio ou auxílio da professora. O tempo utilizado pelo grupo para realizar a atividade foi de aproximadamente um período de aula (50 minutos). $\mathrm{Na}$ turma $\mathrm{B}$, os alunos também não tinham acesso a materiais de apoio ou à professora. Contudo, foram instruídos a utilizar uma estratégia diferente da que estão acostumados. A proposta foi que, antes de iniciar a resolução da situação problema, os alunos deveriam reelaborar o enunciado da questão com uma cena que lhes fosse familiar e, posteriormente, representá-la por meio de um desenho. Somente após esses procedimentos é que deveriam buscar a solução. E, ainda, ao final, deveriam confrontar a resposta encontrada para o problema com o representado no desenho. $\mathrm{O}$ tempo para a execução dessa atividade na turma B foi de dois períodos de aula (1 hora e 30 minutos). Vale lembrar que as duas turmas 
tiveram a oportunidade de realizar os exercícios no mesmo tempo, contudo, a A utilizou apenas 50 minutos e a B 1 hora e 30 minutos.

Os dados coletados com a aplicação das questões nas duas turmas foram classificados e analisados de modo a se proceder a uma comparação entre os dois métodos. Essa comparação levou a uma discussão sobre tais resultados, tendo como referenciais os questionamentos iniciais do estudo.

\section{Resultados e discussões}

A análise dos dados inicia pela apresentação dos resultados pela frequência de resposta. Para isso, são analisadas as resoluções das questões em três situações: não tentou resolver; não resolveu corretamente; e resolveu corretamente. Tais situações são analisadas e apresentadas de forma distinta para cada uma das turmas investigadas, conforme a Tabela 1:

Tabela 1 - Resultado quantitativo da pesquisa.

\begin{tabular}{l|c|c|c|c|c|c}
\hline & \multicolumn{3}{|l|}{ Turma A (TA) - 24 alunos } & \multicolumn{2}{c}{ Turma B (TB) - 25 alunos } \\
\hline Questão & $\begin{array}{c}\text { Não tentou } \\
\text { resolver }\end{array}$ & $\begin{array}{c}\text { Não resolveu } \\
\text { corretamente }\end{array}$ & $\begin{array}{c}\text { Resolveu } \\
\text { corretamente }\end{array}$ & $\begin{array}{c}\text { Não tentou } \\
\text { resolver }\end{array}$ & $\begin{array}{c}\text { Não resolveu } \\
\text { corretamente }\end{array}$ & $\begin{array}{c}\text { Resolveu } \\
\text { corretamente }\end{array}$ \\
\hline 1 & 4 & 20 & - & - & 13 & 12 \\
2 & 4 & 16 & 4 & - & 13 & 12 \\
3 & 7 & 17 & - & 5 & 16 & 4 \\
4 & 9 & 10 & 5 & 10 & 8 & 7 \\
\hline
\end{tabular}

Fonte: Dados de pesquisa, 2015.

Analisando os dados apresentados, tem-se que: nas questões 1 e 2, quatro estudantes (aproximadamente 17\%) da TA não buscaram resolvê-las, ao contrário dos participantes da TB; na questão 3, o percentual de alunos que não responderam à questão foi de, aproximadamente, $30 \%$ na TA e de $20 \%$ na TB; por fim, na questão 4, nove alunos da TA e dez da TB não resolveram a questão.

Essa análise demonstra uma participação maior dos alunos da TB, e, mediante o observado durante a aplicação do teste, infere-se que o tempo teve influência determinante nos dados obtidos sobre a questão 4 da referida turma. Ou seja, para a aplicação da atividade, dispunha-se de até dois períodos, o que, para muitos alunos da TB, não foi suficiente, visto que acabaram deixando a quarta questão sem resposta. Já para a TA, houve tempo de sobra.

Em relação ao comparativo entre o desempenho das turmas na resolução das situações problema, pode-se perceber uma diferença significativa. Dentre os sujeitos da TA que tentaram resolver a questão 1 (20 de 24), nenhum conseguiu resolvê-la corretamente; já na TB, para a mesma situação, foram treze alunos, e doze conseguiram chegar à resposta correta. Na questão 2, dos vinte estudantes da TA que tentaram respondê-la, dezesseis não chegaram à solução, enquanto quatro conseguiram; na TB, dos 25 alunos, treze não conseguiram e doze obtiveram sucesso, seguindo o resultado da questão anterior. Dos dezessete estudantes da TA 
que responderam à questão 3 , nenhum conseguiu resolvê-la, enquanto, na $\mathrm{TB}$, dos vinte alunos que tentaram, dezesseis não conseguiram e quatro chegaram à solução. Por fim, na questão 4, dos quinze sujeitos que responderam à questão na TA, cinco acertaram e dez não, já na TB, de quinze alunos, oito não atingiram o resultado correto, enquanto sete encontraram a solução.

Ao analisar os resultados obtidos quanto ao desempenho, há um aumento não só do número de tentativas de resolução, como também do número de acertos nos alunos em que foi aplicada a proposta de reelaboração e desenho das situações problema, o que é significativo em um contexto de aprendizagem. Contudo, observa-se que o tempo é um fator determinante para possibilitar que os alunos pensem e reflitam sobre suas características pessoais e regulem sua ação. Muitas vezes, uma lista imensa de problemas, como os apresentados nos livros didáticos, inibe os alunos para o trabalho com esse tipo de pensamento, pois isso possibilitaria resolver poucos problemas, o que não é bem-vindo para muitos professores de Física.

Outro viés analisado a respeito da aplicação da proposta na TB é em relação à compreensão dos estudantes acerca das situações físicas. Independentemente de acertos ou erros, o processo de construção registrado pelos estudantes nas folhas de resolução foi significativo e merecedor de uma discussão e reflexão.

Para distinguir o realizado pelos alunos da TA em confronto com os da TB, selecionaram-se imagens das resoluções apresentadas por alguns deles. Estes foram identificados, nas imagens, pela letra "A" seguida de um número quando se refere à TA, e pela letra "B" seguida de um número, quando se trata de aluno da TB. Destaca-se que, por limitações textuais, não é possível apresentar todas as soluções propostas pelos alunos, tendo sido selecionadas as mais expressivas e que possibilitam uma análise em termos do monitoramento e do controle da ação executada pelos alunos, especialmente na TB.

Questão 1: Um bloco sob a ação de uma força horizontal F1, de módulo igual a 10N, permanece em repouso em função da existência de uma força de atrito. Se uma outra força horizontal $\mathrm{F} 2$, de módulo igual a $2 \mathrm{~N}$ e sentido contrário a $\mathrm{F} 1$, for aplicada ao bloco, a força resultante sobre o mesmo será:

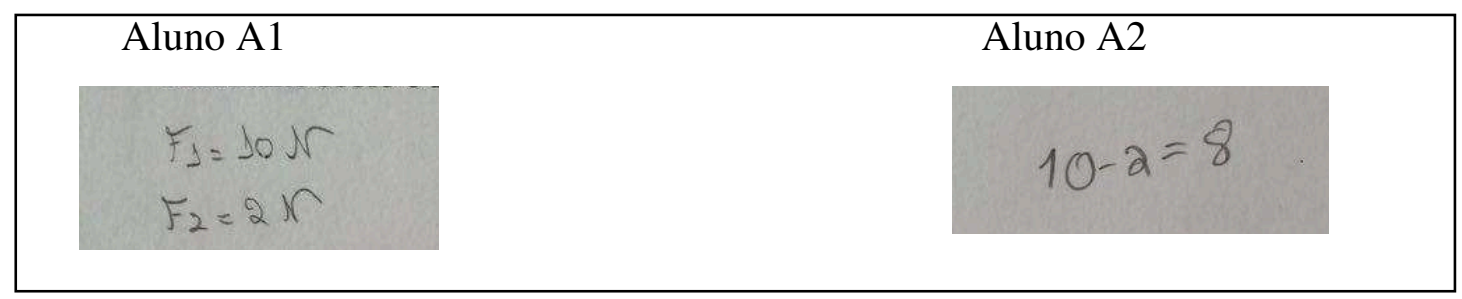

Figura 1 - Respostas dos alunos A1 e A2 para a questão 1.

Fonte: dados de pesquisa, 2015.

Os desenvolvimentos analisados da TA demonstram uma resolução tradicional, ou seja, na qual há prioridade para "encaixar" os dados coletados em alguma fórmula, sem 
atenção para o significado do enunciado do problema e a situação física em foco. No primeiro caso, o aluno A1 apenas extrai os dados numéricos do exercício; os que o texto traz, como a força de atrito, não são registrados pelo estudante, e ele não segue com o desenvolvimento da questão. De modo semelhante, o aluno A2 extrai os dados numéricos e não faz uma análise do contexto do enunciado da situação problema, procedendo a uma resolução que desconsidera informações importantes.

A falta de compreensão da situação física é evidenciada, também, pela falta de unidades, demonstrando, mais uma vez, que nesse caso o importante para o estudante era o resultado numérico.

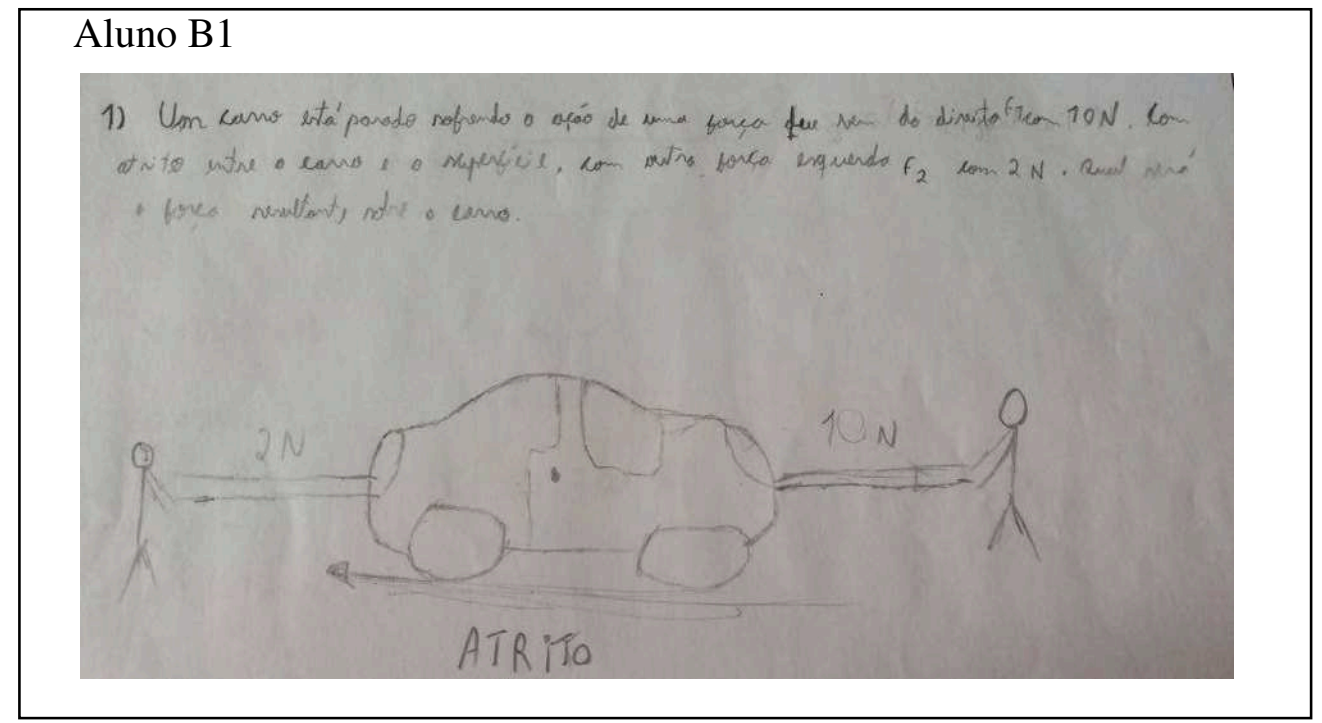

Figura 2 - Respostas do aluno B1 para a questão 1.

Fonte: dados de pesquisa, 2015.

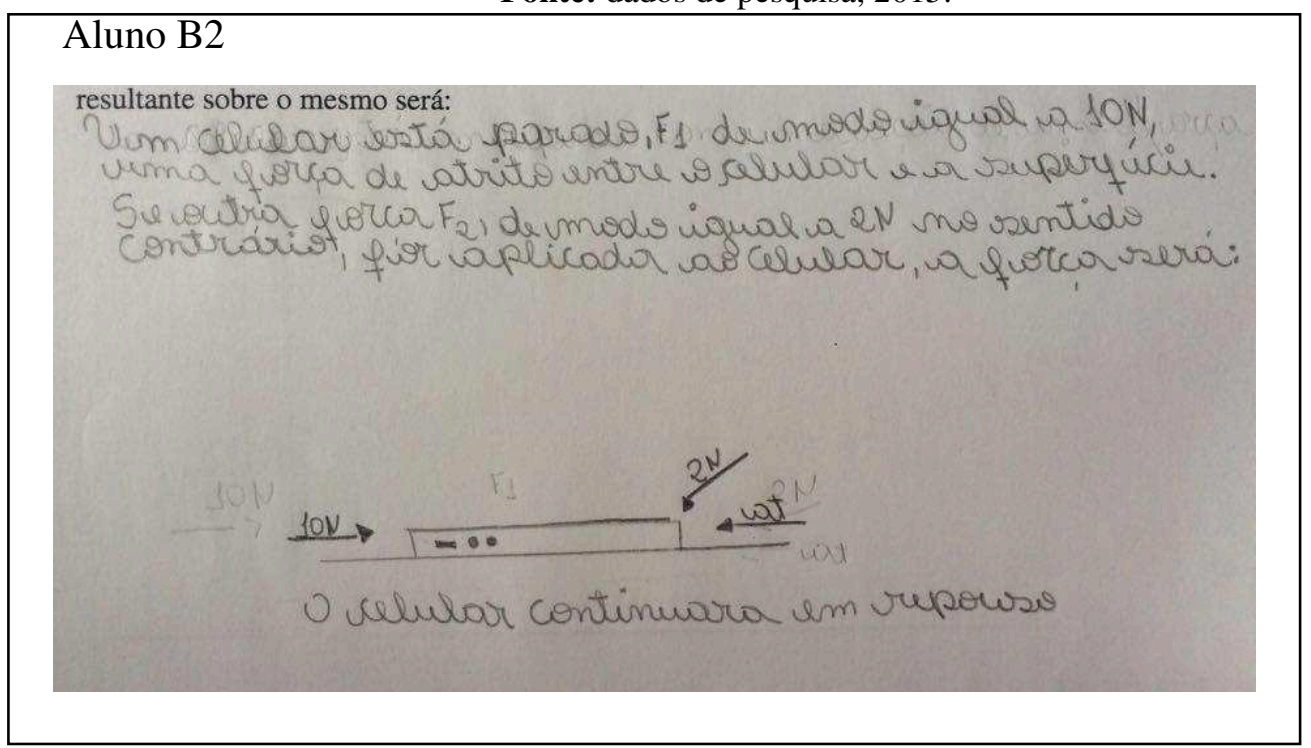

Figura 3 - Respostas do aluno B2 para a questão 1.

Fonte: dados de pesquisa, 2015.

As resoluções apresentadas pelos alunos da TB demonstram ser mais significativas que as apresentadas pela TA. Nas resoluções executadas pelos alunos B1 e B2, pode-se perceber uma diferença interessante a ser considerada pelos professores na hora de avaliarem 
o que o aluno sabe e o que é merecedor de ênfase. No caso do aluno B1, ele não chega a uma resposta final para a questão, contudo, faz uma representação da situação física descrita no enunciado por meio de uma cena que lhe é familiar. Isso se torna válido na medida em que o sujeito estará em contato por mais tempo com a atividade para pensar sobre ela e dar-se conta dos conhecimentos de que dispõe para resolvê-la, bem como de quais precisa aprender. No desenvolvimento do aluno B2, também é possível observar que há um envolvimento maior com a situação, pois ele utiliza um objeto corriqueiro para recriá-la e a desenvolve demonstrando que compreendeu o proposto no enunciado.

Esse contato mais reflexivo com a situação auxilia no desenvolvimento de habilidades metacognitivas relacionadas ao monitoramento e ao controle, pois incentiva o aluno a sair de um nível superficial de compreensão do texto para um nível superior de representação, usando a sua base de conhecimentos. Constata-se, assim, que esta influencia na escolha dos elementos que farão parte de sua nova versão do enunciado e na coerência das unidades com as situações físicas.

Questão 2: Um móvel de $650 \mathrm{~kg}$ de massa desloca-se retilineamente com uma velocidade de $24 \mathrm{~km} / \mathrm{h}$. O movimento é acelerado por $2 \mathrm{~s}$, e a velocidade se altera para 60 $\mathrm{km} / \mathrm{h}$. Qual a resultante das forças que atuam no móvel nesse período?

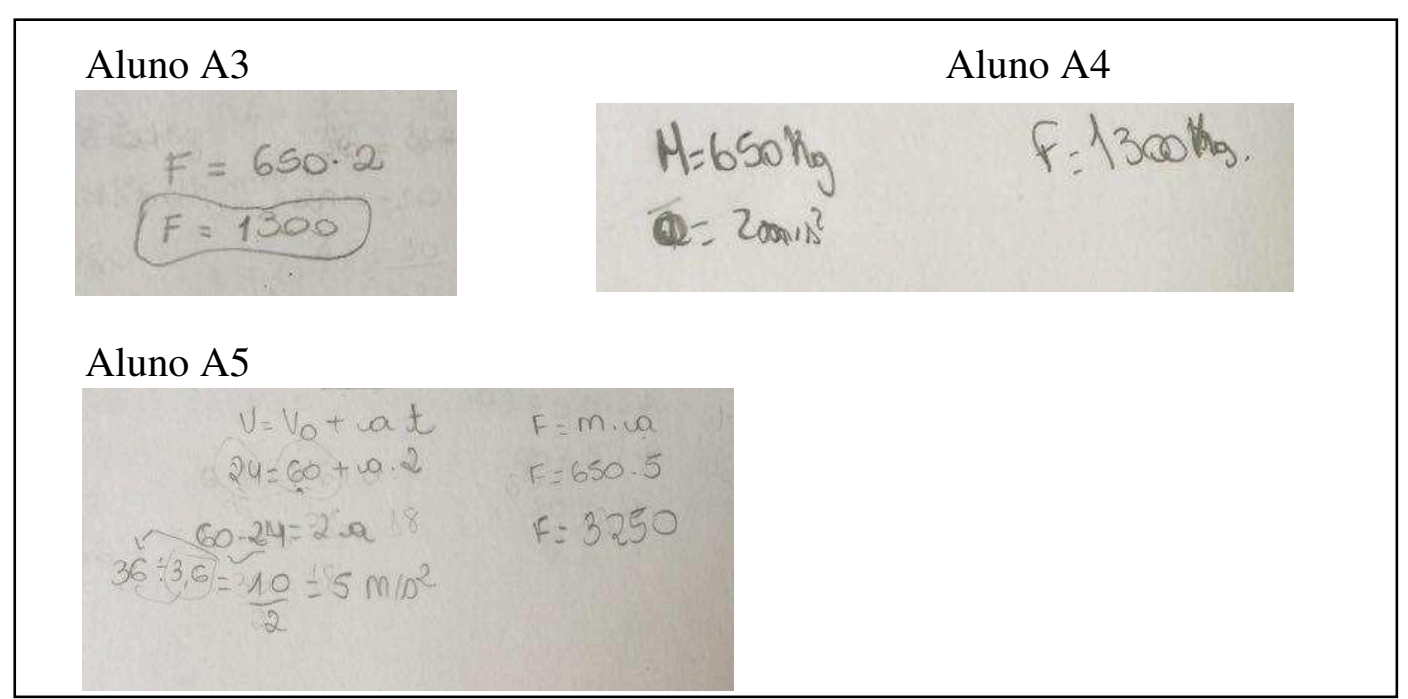

Figura 4 - Respostas dos alunos A3, A4 e A5 para a questão 2.

Fonte: dados de pesquisa, 2015.

Novamente, as resoluções da TA demonstram uma ênfase nos dados numéricos, sem que o sujeito reflita sobre a situação que está sendo descrita. No desenvolvimento do aluno A3, pode-se perceber que ele apenas seleciona dois dados da situação e os encaixa na fórmula do que estava sendo requisitado no problema (força). Portanto, o estudante ignora os outros elementos que a situação traz (velocidades), demonstrando que o objetivo é apenas calcular, sem questionar-se sobre o que está acontecendo fisicamente, ou refletir sobre o próprio enunciado da questão. 
Ao analisar o desenvolvimento do aluno A4, pode-se observar que ele faz a troca de 2 segundos por $2 \mathrm{~m} / \mathrm{s}^{2}$, evidenciando uma dificuldade na interpretação das informações da situação física. Na resolução dos alunos A3 e A5, nota-se a falta de preocupação em colocar a unidade de medida, o que indica que o elemento principal é o cálculo, em detrimento à situação física descrita.

Dentre as três resoluções, a do aluno A5 apresenta resposta correta apesar de haver confusões nos dados coletados. O aluno troca o valor da velocidade inicial apresentada no enunciado com o valor da velocidade final e ao final procede a uma inversão de sinal arbitrário que acaba resultando no valor desejado para a aceleração. Mesmo que esse resultado seja o esperado e somente com base nessas informações, não há possibilidade de se realizar inferências acerca das representações que o sujeito faz da situação problema, pois ele pode ter simplesmente decorado o procedimento para a resolução desse tipo de questão. Diante disso, podem ser analisados apenas elementos relacionados ao monitoramento e à autorregulação da aprendizagem, como é o caso da falta da unidade de referência.

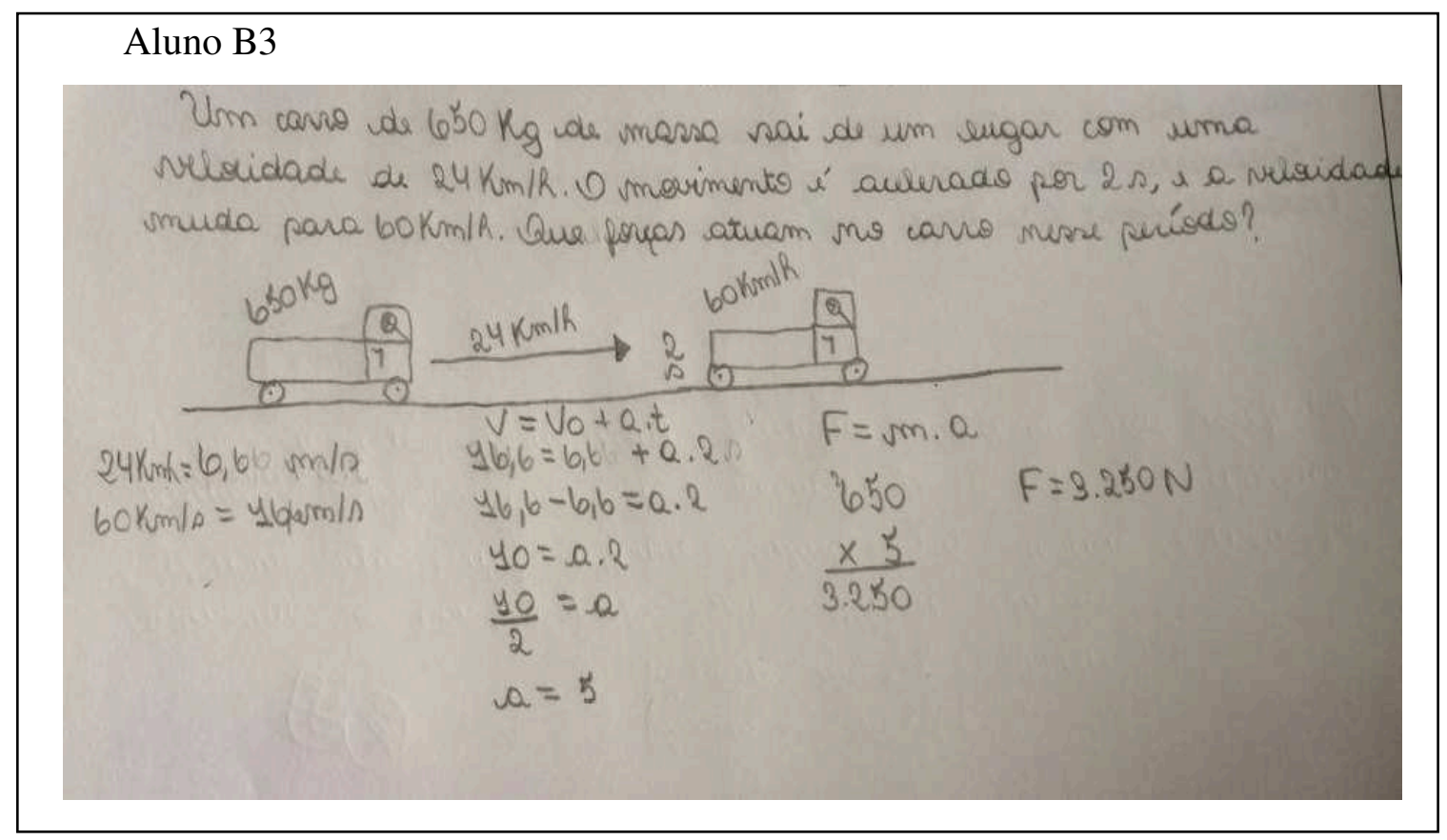

Figura 5 - Respostas do aluno B3 para a questão 2.

Fonte: dados de pesquisa, 2015. 


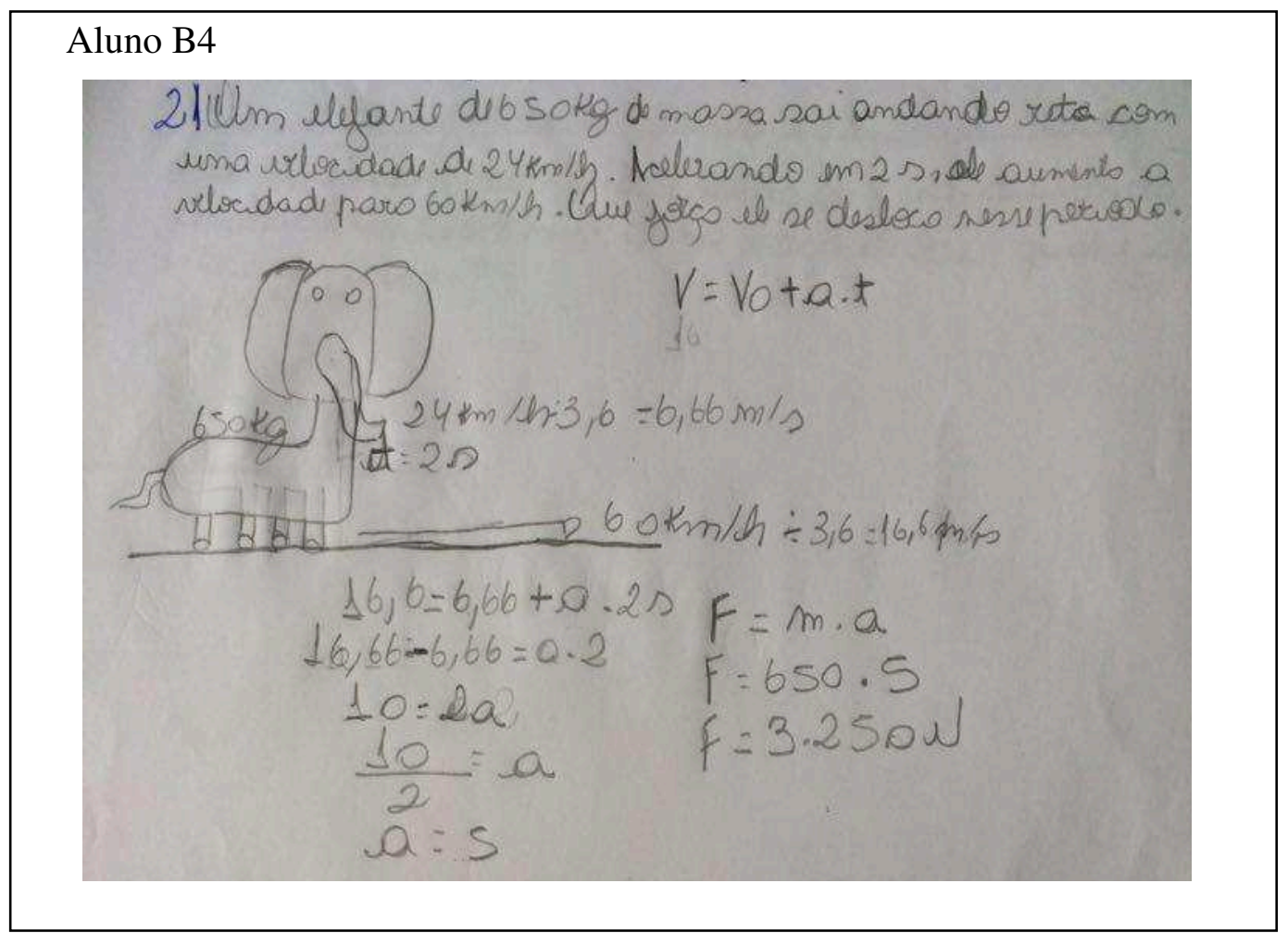

Figura 6 - Respostas do aluno B4 para a questão 2.

Fonte: dados de pesquisa, 2015.

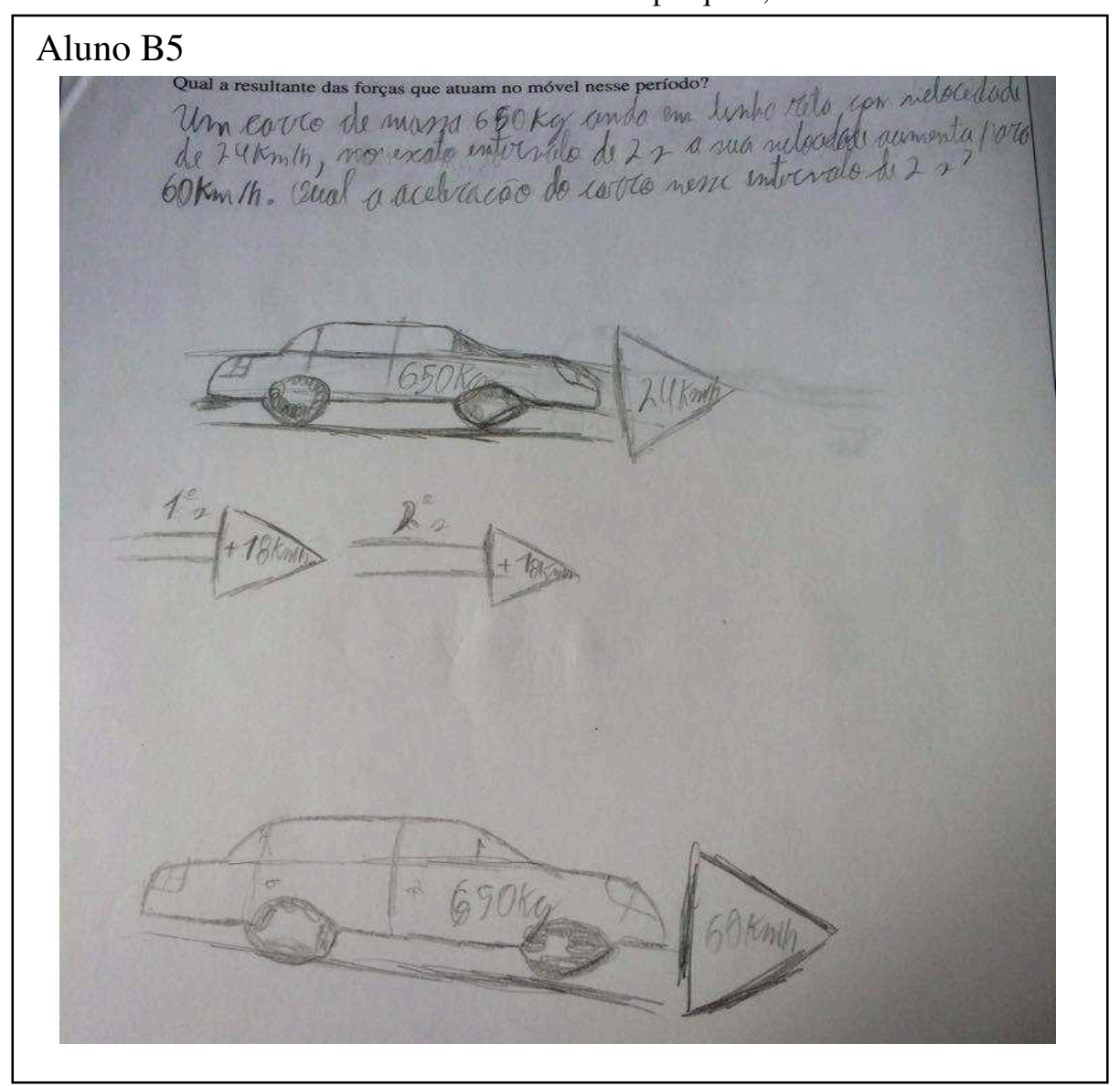

Figura 7 - Respostas do aluno B5 para a questão 2.

Fonte: dados de pesquisa, 2015.

Nas resoluções dos alunos B3 e B4, observa-se que a primeira situação apresenta-se como mais coerente. Contudo, a do aluno B4 denota uma preocupação maior em termos de 
escolher um móvel com a massa próxima à especificada no problema e que possa atingir a velocidade apresentada. Acredita-se que essa discrepância entre as situações representadas pelos alunos relaciona-se às experiências cotidianas - por exemplo, um carro faz parte da sua vivência, enquanto um elefante correndo está mais distante de suas experiências diárias.

O aluno B5, por sua vez, não consegue chegar à resposta final da situação problema. Todavia, ao analisar a representação, percebem-se os elementos que ele compreende, por exemplo, a aceleração. Essa estratégia pode dar subsídios aos professores quanto à identificação do conhecimento dos estudantes, pois, em vez de apenas deixar em branco, por não saber resolver a situação problema, o aluno faz a representação com base no que aprendeu, oportunizando que o professor explore as lacunas que ele apresenta.

Nas três situações, observa-se coerência das unidades de medida utilizadas para cada grandeza. Pressupõe-se, com isso, que essa diferença observada entre as resoluções da TA e da TB deve-se à possibilidade de tomar consciência do significado dessas unidades para então atribuí-las às grandezas físicas e da capacidade de monitorar os processos a partir das representações dos estudantes.

Questão 3: Duas forças de mesma direção, mas de sentidos opostos, atuam sobre um corpo de massa $10 \mathrm{~kg}$, imprimindo-lhe uma aceleração de $4 \mathrm{~m} / \mathrm{s}^{2}$. Se uma das forças tem módulo $20 \mathrm{~N}$, qual é o módulo da outra?

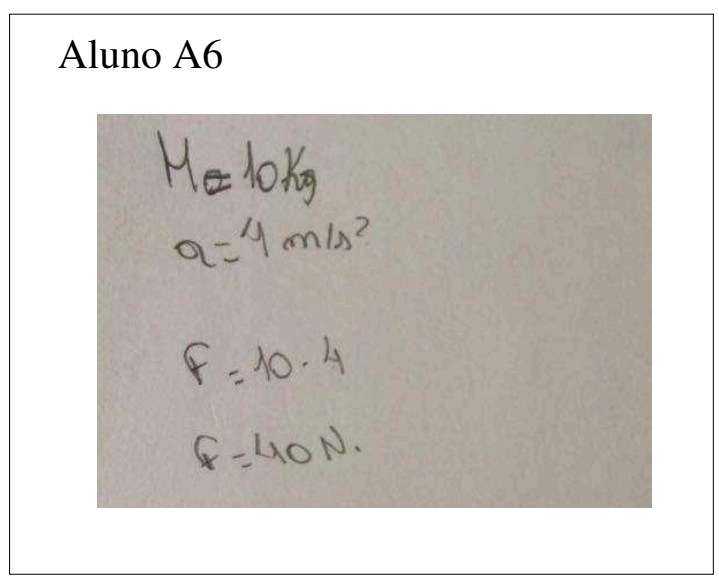

Figura 8 - Respostas do aluno A6 para a questão 3.

Fonte: dados de pesquisa, 2015.

$\mathrm{Na}$ resolução apresenta pelo aluno A6, constatam-se elementos semelhantes aos observados nas análises das primeiras questões. Vale lembrar, porém, que nessa questão nenhum estudante da TA chega à resposta correta. $\mathrm{O}$ exemplo de resposta ilustrado anteriormente revela o modo pelo qual os alunos tentam resolver a questão. O apresentado por A6 leva em conta apenas algumas informações da situação problema, desconsiderando dados implícitos na interpretação do enunciado e, também, dados numéricos, demonstrando novamente a ênfase dos estudantes em resolverem uma fórmula depreciando outros pontos relevantes da questão. 


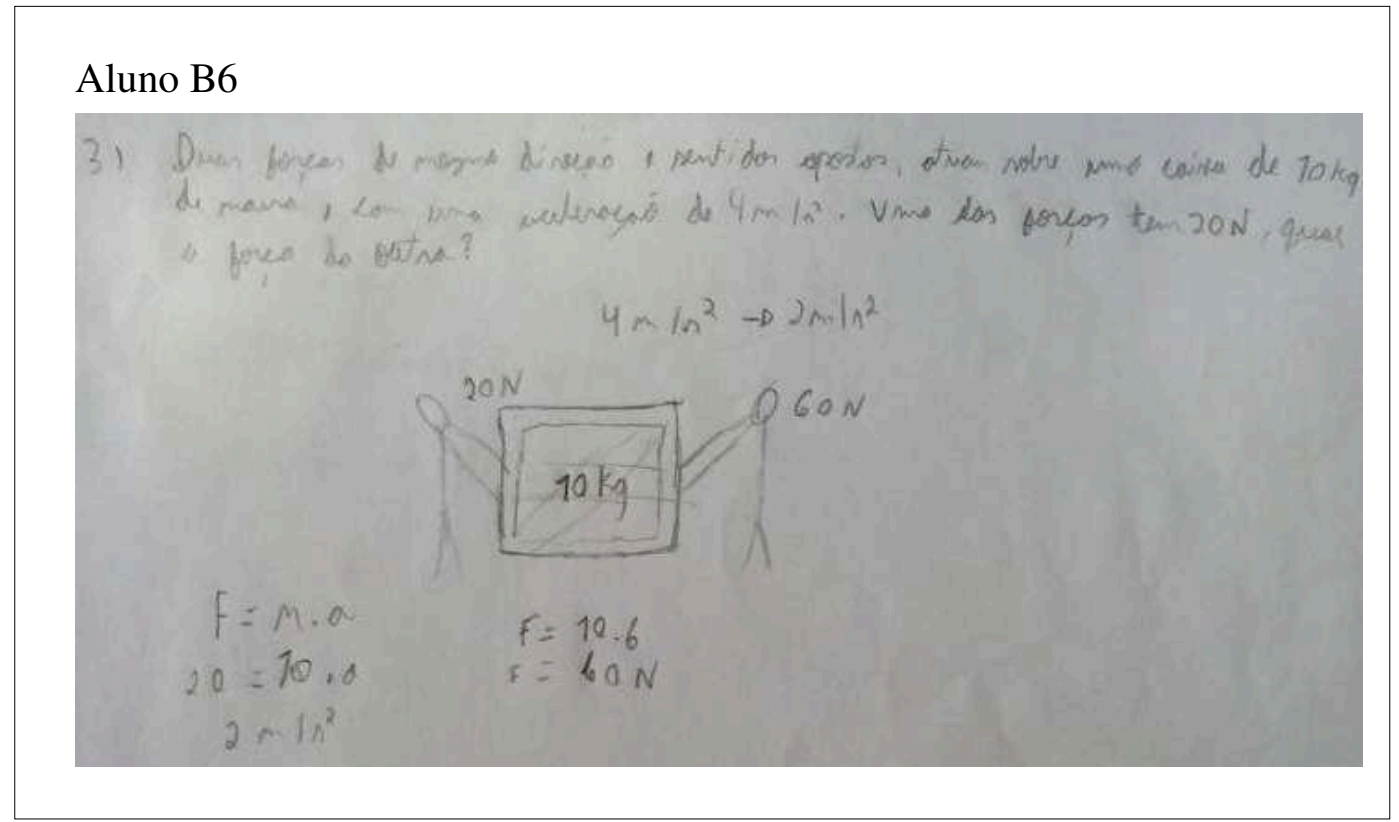

Figura 9 - Respostas do aluno B6 para a questão 3.

Fonte: dados de pesquisa, 2015.

Constata-se, pelo apresentado, que o aluno B6 consegue resolver a situação problema. Acredita-se que a reconstrução da situação e o desenho tenham contribuído para isso, possibilitando uma leitura mais atenta e o acionamento de esquemas mentais relacionados a esse conhecimento específico.

Questão 4: A partir do instante $\mathrm{t}=0$, um corpo de $5 \mathrm{~kg}$, inicialmente em repouso, fica sujeito a uma força resultante constante de módulo 30N. a) Qual é o módulo de aceleração adquirida pelo corpo? B) Qual é a velocidade escalar do corpo no instante $\mathrm{t}=3 \mathrm{~s}$ ?

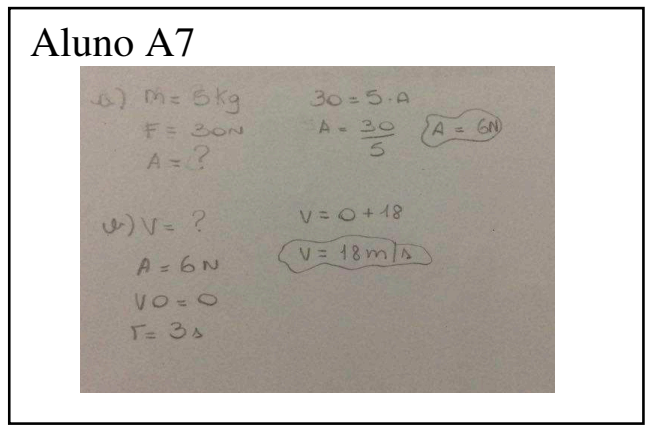

Figura 10 - Respostas do aluno A7 para a questão 4.

Fonte: dados de pesquisa, 2015.

As resoluções da questão 4 mostram, mais uma vez, os aspectos analisados nas anteriores. Nessa questão, um número próximo de alunos chega às respostas corretas, entretanto, ao verificar o desenvolvimento das questões, nota-se que, embora os estudantes da turma A realizem os procedimentos de cálculo corretos, a situação física não recebe a sua atenção. Como exemplo, cita-se a resolução do aluno A7, que encontra o valor numérico correto para o cálculo de aceleração, mas utiliza unidade de força. Nesses casos, observa-se a 
falta de avaliação dos alunos acerca de suas próprias ações, bem como a carência de uma reflexão sobre o que é proposto em relação às grandezas envolvidas na questão.

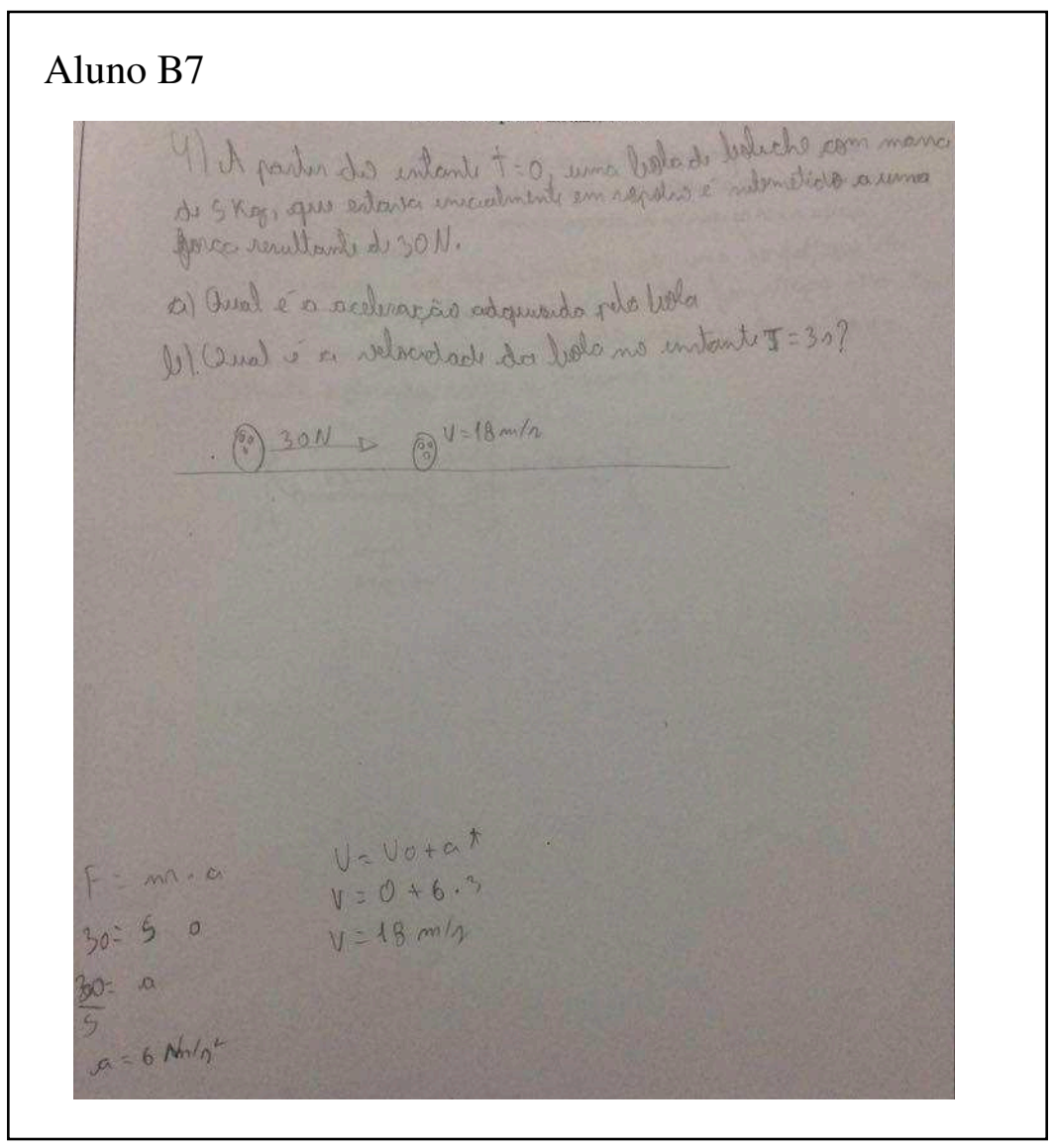

Figura 11 - Respostas do aluno B7 para a questão 4.

Fonte: dados de pesquisa, 2015.

Na resolução do aluno B7, percebe-se que ele busca aproximar, em sua reelaboração do enunciado, uma equivalência com as grandezas físicas que a situação traz. Nesse sentido, demonstra ter resgatado o seu conhecimento acerca dos conceitos de massa, aceleração, força e velocidade para garantir coerência ao que propõe.

\section{Considerações finais}

Uma vez que um dos fatores apontados como responsáveis pelo fracasso da utilização de resolução de problemas nas aulas de Física está na dificuldade dos estudantes em compreenderem os enunciados, devido à distância entre estes e as suas experiências (GÓMEZ-FERRAGUD et al., 2016), a estratégia utilizada mostra-se promissora para auxiliálos. A proposta possibilita uma aproximação das situações problema à vivência cotidiana dos estudantes, pois, ao reelaborá-las, é necessário fazer um resgate de conhecimentos prévios e analisar qual deles se enquadra no solicitado pelo exercício.

Ao provocar a tomada de consciência dos conhecimentos relacionados à situação física, por meio do pensamento e da reflexão sobre o apresentado, a proposta fornece indícios 
de que o monitoramento e a supervisão dos próprios conhecimentos são capazes de auxiliar os estudantes na compreensão dos conteúdos. Em outras palavras, o fato de levar os estudantes a pensar a situação física e aproximá-la da vivência, favorece a regulação de sua própria aprendizagem. Tal fato encontro suporte no mencionado por Rosa (2011) a qual, conforme mencionado na introdução do estudo, atribui a monitoração a capacidade de controlar a ação a ser executada de modo a verificar se está adequada para atingir o objetivo proposto, de modo a alterar o percurso se necessário.

A reelaboração do enunciado estimula a evocação do pensamento metacognitivo, e o desenho permite ao aluno expor suas representações mentais e, ao mesmo tempo, melhor elaborá-la mediante a tomada de consciência do seu conhecimento implicado naquela situação problema. Esse exercício de reelaborar e representar mentalmente a situação apresentada é uma tarefa difícil especialmente para os alunos com dificuldade de aprendizagem em Física (COLEONI et al., 2001) e, portanto, exercitá-la com os alunos passa a ser uma tarefa que poderá render êxito na aprendizagem.

Relacionando a estratégia adotada neste estudo com os níveis de compreensão propostos por esses autores, a proposta demonstra atingir um terceiro nível de compreensão, ou seja, o nível de conhecimentos necessário para construir as representações mentais. Nesse nível o sujeito estará ancorando as novas informações nas que já estão disponíveis em sua estrutura cognitiva, possibilitando, assim, uma aprendizagem significativa durante a resolução de problemas, conforme mencionado na introdução deste estudo. Afinal, o sujeito precisa entender o enunciado e ir além da estrutura sintática do texto, pois necessita associar elementos de esquemas já existentes na sua estrutura cognitiva para reelaborar a situação.

As situações problema do tipo lápis e papel são tipicamente trabalhadas nas aulas de Física, e a possibilidade de reelaborá-las permite que os alunos deem significado às informações genéricas que geralmente esse modelo traz. É importante considerar, também, que a aplicação dessa estratégia não exige que os professores mudem radicalmente sua prática, facilitando a sua inserção no cotidiano escolar, agregada à possibilidade do desenvolvimento de um pensamento metacognitivo.

\section{Referências}

BRASIL. Parâmetros curriculares nacionais: Ciências da Natureza, Matemática e suas Tecnologias. Secretaria de Educação Fundamental. Brasília: MEC / SEF, 1998.

CAMPANARIO, J. M.; OTERO, J.C. Más allá de las ideas previas como dificultades de aprendizaje: las pautas de pensamiento, las concepciones epistemológicas y las estrategias metacognitivas de los alumnos de ciencias. Enseñanza de las Ciencias, v. 18, n. 2, p. 155-169, 2000 . 
CHI, M.T.; GLASER, R.; REES, E.. Expertise in problem solving. In: STERNBERG, R. J. (Ed.). Advances in the psychology of human intelligence. v. 1. Hilsdale, N.J.: Erlbaum, 1982.

CLEMENT, L.. Resolução de problemas e o ensino de procedimentos e atitudes em aulas de Física. 2004. Dissertação de mestrado em Educação - Universidade Federal de Santa Maria, 2004.

CLEMENT, L.; TERRAZAN, E. A. Resolução de problemas de lápis e papel numa abordagem investigativa. Experiências em Ensino de Ciências, v. 7, n. 2, p. 98-116, 2012.

COLEONI, E. A. ; OTERO, J. C.; GANGOSO, Z. E.; HAMITY, V. H. La construcción de la representación en la resolución de un problema de física. Investigações em Ensino de Ciências, v. 6, n. 3, p. 285-298, 2001.

COSTA, S. S. C.; MOREIRA, M. A. Resolução de problemas I: diferença entre novatos e especialistas. Investigações em Ensino de Ciências, v. 1, n. 2, p. 153-184, 1996.

COSTA, S. S. C.; MOREIRA, M. A. Resolução de problemas IV: estratégias para resolução de problema. Investigações em Ensino de Ciências, v. 2, n. 3, p. 176-192, 1997.

COSTA, S. S. C.; MOREIRA, M. A. Atualização da pesquisa em resolução de problemas: informações relevantes para o ensino de Física. In: ENCONTRO ESTADUAL DE ENSINO DE FÍSICA. 2005. Atas... Porto Alegre: Instituto de Física-UFRGS, 2005. 1

FLAVELL, J. H.; WELLMAN, H. M. Metamemory. In: KAIL, R. V.; HAGEN, J. (Eds.). Perspectives on the development of memory and cognition. Hillsdale, New Jersey: Lawrence Erlbaum Associates, 1977. p. 3-33

FONSECA, V. Introdução às dificuldades de aprendizagem. Artes Médicas: Porto Alegre, 1995.

GIL, A. C. Como elaborar projetos de pesquisa. 5. ed. São Paulo: Atlas, 2008.

GÓMEZ-FERRAGUD, C.; SANJOSÉ, V.; SOLAZ- PORTOLÉ, J. Estudios sobre comprensión y control de la comprensión en resolución de problemas académicos. Revista Enseñanza de la Física, v. 28, n.1, 2016.

LEITE, L.; ESTEVES, E. Ensino orientado para a aprendizagem baseada na resolução de problemas na licenciatura em ensino de Física e Química. In: CONGRESSO GALAICO PORTUGUÊS PSICOPEDAGOGIA. Universidade do Minho. Instituto de Educação e Psicologia. Centro de Investigação em Educação, 2005, 7, p. 1751 - 1768. < http://hdl.handle.net/1822/5537>

LESTER, F. K. Considerações sobre a resolução de problemas em matemática. Boletim de Educação Matemática, v. 4, 1985.

MOREIRA, M. A.; MASINI, E. F. S. Aprendizagem significativa: a teoria de David Ausubel. 2. ed. São Paulo: Centauro, 2006.

NETO, A. J.; VALENTE, M. O. Disonancias pedagógicas en la resolución de problemas de física. Enseñanza de las Ciencias, v. 19, n. 1, p. 21-30, 2001.

PEDUZZI, L. O. Q; ZYLBERSZTAJN, A.; MOREIRA, M. A.. As concepções espontâneas, a resolução de problemas e a história da ciência numa sequência de conteúdos em mecânica: o 
referencial teórico e a receptividade de estudantes universitários à abordagem histórica da relação força e movimento. Revista Brasileira de Ensino de Física, v. 14, n. 4, p. 239-246, 1992.

POLYA, G. O ensino por meio de problemas. Revista do Professor de Matemática, v. 7, p. 11-16, 1985.

ROSA, C. T. W. A metacognição e as atividades experimentais no ensino de Física. 2011. Tese de Doutorado em Educação Científica e Tecnológica - Universidade Federal de Santa Catarina, Florianópolis, 2011.

ROSA, C. T. W. Metacognição no ensino de Física: da concepção à aplicação. Editora UPF: Passo Fundo, 2014.

SOUSA, C. M. S. G.; FÁVERO, M. H. Um estudo sobre resolução de problemas de física em situação de interlocução entre um especialista e um novato. In: ENCONTRO DE PESQUISA EM ENSINO DE FÍSICA. 2002. Atas... Sociedade Brasileira de Ensino de Física, São Paulo, 2002. 8

SOUSA, C. M. S. G.; FÁVERO, M. H. Concepções de professores de física sobre resolução de problemas e o ensino da Física. Revista Brasileira de Pesquisa em Educação em Ciências, v. 3, n. 1, p. 58-69, 2003.

TRIVIÑOS, A. N. S. Introdução à pesquisa em ciências sociais: a pesquisa qualitativa em educação. 4. ed. São Paulo: Atlas, 1994.

VIEIRA, E. Representação mental: as dificuldades na atividade cognitiva e metacognitiva na resolução de problemas matemáticos. Psicologia: reflexão e crítica, v. 14, n. 2, p. 439-448, 2001 .

\section{SOBRE AS AUTORAS}

CLECI TERESINHA WERNER DA ROSA. Doutora em Educação Científica e Tecnológica, pela Universidade Federal de Santa Catarina, atua como docente permanente no Programa de Pós-Graduação em Ensino de Ciências e Matemática e no Programa de PósGraduação em Educação ambos da Universidade de Passo Fundo-RS. Investiga e orienta trabalhos na área de processos educativos e cognição e no campo da didática das ciências.

CAROLINE MARIA GHIGGI. Mestranda no Programa de Pós-Graduação em Ensino de Ciências e Matemática, é graduada em Física-Licenciatura e professora da educação básica no município de Passo Fundo-RS.

Recebido: 15 de julho de 2016.

Revisado: 05 de fevereiro de 2017.

Aceito: 16 de fevereiro de 2017. 